\title{
1 A wealth of opportunities: an ethnographic study on learning to deliver high-value, cost-
}

2 conscious care.

3 Stammen $^{a}$, Janssen $^{b}$, Bressers $^{a}$, Driessen $^{a}$, Stassen $^{c}$, Stalmeijer $^{a}$, Scheele $^{d, e}$.

$5 \quad{ }^{\text {a }}$ School of Health Professions Education (SHE), Department of Educational Research and

6 Development, Maastricht University, Maastricht, Limburg, The Netherlands; ${ }^{b}$ Faculty of

7 Health, Medicine and Life sciences, Maastricht university, ${ }^{\mathrm{c}}$ Department of Surgery, Maastricht

8 University Medical Center, Maastricht, The Netherlands, ${ }^{e}$ Athena Institute, VU School of

9 Medical Sciences, Amsterdam UMC, Amsterdam, The Netherlands, ${ }^{\mathrm{e}}$ OLVG Amsterdam,

10 Amsterdam, The Netherlands

Lorette A. Stammen (M.D.) is a family medicine resident and PhD-candidate in the field of

Medical Education, School of Health Professions Education (SHE), Department of Educational

Research and Development, Maastricht University, Maastricht, Limburg, The Netherlands,

l.stammen@maastrichtuniversity.nl

https://orcid.org/0000-0003-1528-546X

Linda M.E. Janssen (M.D.) is a recently graduated physician, currently working in geriatric

health care. At time of the study, she was a graduate student at the faculty of health, medicine and life sciences, Maastricht University, Limburg, The Netherlands,

Lme.janssen@maastrichtuniversity.nl

Guusje Bressers (Msc) is an anthropologist and PhD-candidate in the field of Medical 
medRxiv preprint doi: https://doi.org/10.1101/19011916; this version posted November 15, 2019. The copyright holder for this preprint (which was not certified by peer review) is the author/funder, who has granted medRxiv a license to display the preprint in perpetuity.

It is made available under a CC-BY 4.0 International license.

$1 \quad$ https://orcid.org/0000-0003-4073-9312

2 Erik W. Driessen (PhD) is professor of Medical Education, Department of Educational

3 Research and Development, Maastricht University, Maastricht, Limburg, The Netherlands,

$4 \quad$ e.driessen@maastrichtuniversity.nl

$5 \quad$ https://orcid.org/0000-0001-8115-261X

6

$7 \quad$ Laurents P.S. Stassen $(P h D)$ is professor of Medical Education and a gastro-intestinal

8 surgeon, Department of Surgery, Maastricht University Medical Center, Maastricht, The

$9 \quad$ Netherlands, lps.stassen@mumc.nl

10 https://orcid.org/0000-0002-3383-9035

11 Renée E. Stalmeijer (PhD)is assistant professor, and qualitative researcher, School of Health

12 Professions Education (SHE), Department of Educational Research and Development,

13 Maastricht University, Maastricht, Limburg, The Netherlands,

$14 \quad$ r.stalmeijer@maastrichtuniversity.nl

$15 \quad$ https://orcid.org/0000-0001-8690-5326

Fedde Scheele (PhD) is professor of Health Systems Innovation and Medical Education at the

17 Athena Institute, VU School of Medical Sciences, Amsterdam UMC, Amsterdam, The

18 Netherlands and a gynaecologist at the OLVG hospital Amsterdam, Amsterdam, The

19 Netherlands, f.scheele@olvg.nl

20 https://orcid.org/0000-0001-9593-257X

21

22 Corresponding author:

23 Lorette A. Stammen, MD

24 Department of Educational Development and Research,

25 Faculty of Health, Medicine and Life Sciences, Maastricht University,

26 PO Box 616, 6200 MD Maastricht, the Netherlands; 
1 telephone: +31 43388 5741; email: 1.stammen@maastrichtuniversity.nl.

2

3

\section{Abstract}

5 Objective: Since physicians' behaviour determines up to $80 \%$ of total healthcare expenditures,

6 training residents to deliver high-value, cost-conscious care is essential. Residents acknowledge

7 the importance of high-value, cost-conscious care-delivery, yet perceive training to be

8 insufficient. We designed an observational study to gain insight into how the workplace setting

9 relates to residents' high-value, cost-conscious care-delivery.

Design: This ethnographic study builds on 175 hours of non-participant observations including informal interviews, 9 semi-structured interviews and document analysis.

Setting: Department of obstetrics and gynaecology in an academic hospital in the Netherlands.

Population or sample: 21 gynaecology residents.

Methods: Iterative analysis process of fieldnotes, interview transcripts and documents, including open-coding, thematic analysis and axial analysis by a multidisciplinary research team.

Results: Residents rarely consider health care costs, and knowledge regarding costs is often absent. Senior consultants guide residents while balancing benefits, risks and costs, with or without explicating their decision-making process. Identified learning opportunities are elaboration on questions raised concerning high-value, cost-conscious care, checking information about costs that are used in discussions about high-value, cost-conscious care, and having a more open and explicit discussion about high-value, cost-conscious care.

Conclusion: Our study emphasizes that the opportunities and potential to train residents to 
1 capitalizing on these opportunities. We suggest departments to consult external experts to

2 facilitate discussions regarding high-value, cost-conscious care to contribute to informal

3 learning and to create a workplace setting in which high-value, cost-conscious care-delivery is

4 prioritized.

5 Funding: none

6 Keywords: medical education, high-value, cost-conscious care, residency training, ethnography.

25

26

27

28

29 


\section{Introduction}

2 Rising healthcare expenditure significantly impact the sustainability of healthcare systems. ${ }^{1-3}$

3 Limiting costs whilst ensuring the quality of care is therefore high on the political and medical

4 agenda. ${ }^{4}$ Since physicians' behaviour determines up to an estimated $80 \%$ of total healthcare

5 expenditures, shaping the behaviour of future physicians is a potentially valuable intervention

6 for ensuring delivery of high-value, cost-conscious care (HV3C). ${ }^{5-9} \mathrm{HV} 3 \mathrm{C}$ is defined as "care

7 that aims to assess the benefits, harms, and costs of interventions' that leads to 'care that adds

8 value' for the individual patient and the population in general. ${ }^{10} \mathrm{HV} 3 \mathrm{C}$ is characterized by

9 three key principles: 1 ) it avoids wasteful care that has no added value for the patient,

10 therewith reducing unnecessary costs; 2) it aligns with the personal preferences and needs of

11 the patient; and 3) it is based on the latest evidence..$^{2,10-12}$

13 Campaigns such as Choosing Wisely ${ }^{13}$ and Less is More ${ }^{14}$ have advanced awareness of

14 unnecessary treatments and procedures and have led to a variety of initiatives, including

15 educational interventions. High-profile organizations such as the Accreditation Council for

16 Graduate Medical Education (ACGME), the Canadian Medical Education Directives for

17 Specialists (CanMEDS), together with American College of Physicians (ACP) and General

18 Medical Council (GMC) also aim to prepare residents for their future roles in HV3C

19 delivery. ${ }^{15-17}$ A general aim of these organizations is to incorporate $\mathrm{HV} 3 \mathrm{C}$ in the training of

20 physicians, residents and medical students. ${ }^{3,16}$ While initiatives mainly focused on formal

21 education, ${ }^{8,18}$ residency training takes place in the clinical workplace where training is mostly

22 informal. $^{19}$

24 Workplace based learning in the area of HV3C is increasingly investigated ${ }^{9,20}$ and results indicate that residents perceive $\mathrm{HV} 3 \mathrm{C}$ training to be insufficient. ${ }^{9}$ These findings are worrying, 
1 since workplace based learning covers the majority of residency training ${ }^{21}$ and lessons from

2 graduate medical education persist long into practice. ${ }^{22-24} \mathrm{We}$ aimed to build on and expand this

3 research by obtaining a real-life perspective on the workplace setting. Therefore, we designed

4 an observational study to gain insight into how the workplace setting is related to residents'

5 HV3-delivery.

\section{Methods}

8 Research design

9 We conducted an ethnographic study to gain insight into how the workplace setting is related 10 to residents' HV3C-delivery. Ethnography is a qualitative research methodology, commonly 11 used to study cultures, by which data is collected through fieldwork. ${ }^{25,26}$ In this case fieldwork

12 consisted of non-participatory observations, informal interviews, semi-structured interviews

13 and document analysis to generate insight into the sample population's views, motives and

14 actions in the real-life setting. ${ }^{25,27}$ For a more elaborate description of ethnography as a

15 methodology and insight in the iterative process of data-collection and data-analysis, we

16 would like to refer to Appendix A.

The fieldwork was conducted in an academic hospital in the Netherlands at a Department of

20 Obstetrics and Gynaecology. At the time of the study, a national government-subsidized

21 project was running aimed at increasing awareness of $\mathrm{HV} 3 \mathrm{C}$ during residency training ${ }^{28}$. This

22 project provided educational material and e-learning opportunities to stimulate residents to

23 voluntarily set up projects to improve HV3C delivery in their department. During our data-

24 collection no formal education was present to teach residents HV3C-delivery. 
2 Subjects

3 All 21 resident physicians working in the gynaecology department at the time of our study

4 participated. Prior to the study they were informed about the research by letter and attended a

5 short presentation during the morning handover, in which we explained the primary research

6 goal as 'we want to gain insight into how the workplace setting is related to residents' HV3C-

7 delivery'. Written informed consent was obtained from all participating residents. The Ethical

8 Review Board of the Netherlands Association for Medical Education approved this study on

9 August 24, 2017, under file number 881.

Data collection

12 The second author (LMJ) shadowed gynaecology residents in daily practice for 175 hours

13 during the period of three months. LMJ accompanied the residents during patient consultations,

14 surgical procedures, deliveries and medical rounds, and attended meetings, e.g. morning reports,

15 educational activities and (multidisciplinary) seminars, as well as lunch and coffee breaks.

16 These non-participant observations (i.e. the researcher was not involved in care delivery)

17 focused on residents' behaviour, conversations and situations regarding care delivery.

18 Observations were followed by unstructured and ad hoc informal interviews with the aim of

19 gaining thorough comprehension of the context and rationale of the observed moments. ${ }^{29,30}$

20 Additionally, semi-structured interviews were held (by LMJ and LAS) with nine purposively

21 selected participants to gain additional information about specific observed situations and the

22 department in general from representatives of the observed population. Participants were sampled based on the level of involvement in discussions and conversations regarding $\mathrm{HV} 3 \mathrm{C}$,

24 both residents and staff-members with high and low levels of involvement were selected. All 
1 interviews were audio-recorded and transcribed verbatim. Document analysis of hospital and

2 national protocols and patient charts was executed to see, when residents or supervisors referred

3 to protocols, whether their claims were supported as well as whether the decision-making

4 process was retraceable.

6 Observed behaviour and conversations were thickly described, written up in detailed, context-

7 sensitive and locally informed fieldnotes about the observed events ${ }^{25,31}$. Data collection

8 involved iterative cycles of data collection and analysis, combining observations, interviews

9 and analysis together with the research team (see Appendix B). ${ }^{25,30}$ The iterative process of data collection discontinued when data-saturation was reached, meaning data-analysis did not

11 result in new concepts and an adequate understanding of key concepts was gained. ${ }^{26}$ Data

12 saturation was reached after approximately 175 hours of observation and 9 semi-structured 13 interviews.

Data-analysis

As is common in ethnography, the data were analysed iteratively (see Appendix B) starting with line-by-line open coding by LMJ, LAS and GB. ${ }^{25,32}$ The next steps were thematic and axial analyses, in which we identified central themes and relationships between the various themes. As a result of team discussions, we gradually adapted the focus of the observational themes and conducted semi-structured interviews in order to deeper our understanding of the data. Additionally, FS checked if the observations represented national care delivery and not a specific regional setting. We are aware of the influence of the researchers' background on the process of data-collection and data-analysis, to increase transparency we included a reflexivity-paragraph in Appendix A. 


\section{Results}

2 The consideration of benefits, risks and health care costs in daily practice

3 When protocols, guidelines or regional agreements failed to provide clear direction towards

4 care delivery, or when new scientific information became accessible, health care professionals

$5 \quad$ needed to decide which care delivery was considered 'appropriate'. Health care professionals

6 then considered pros and cons, including concerns for patients, consequences of a missed

7 diagnosis, respect for autonomy of patients, burden of testing or treatment, influence of

8 quality of life and long-term health benefits. We rarely observed attention for health care

9 costs, or conversations regarding who would eventually pay for those costs. In cases in which

10 costs were included in the process of balancing pros and cons of health care services, the

11 absence of knowledge regarding costs became apparent. Questions regarding financial costs

12 arose when residents and senior consultants discussed a scientific article, reviewed the

13 protocol, or discussed the necessity of structural testing. Observations demonstrated that

14 financial reasoning did not influence the process of decision making. We did not observe occasions in which health care costs were checked as a result of such discussions.

It is the end of the morning round and medical students, supervised by the resident-in-training are critically appraising a procedure. The resident noticed differences between the value and

19 use of repetitive PCR-ratio (protein-to-creatine) determined in single voided urine versus ACRratio in 24-hour-collected urine for diagnosing pre-eclampsia $(P E)$ in their training region. ratio) and ACR (24-hour albumin-to-creatinine ratio).

24 S3: And what about the cost?

25 A26: That's a good one, we should actually check that in the lab. 
2 Document analysis demonstrated that costs were not checked nor was the protocol adapted as a

3 result of the discussion. (Fieldnotes, February 21, 2018)

5 The influence of the senior consultant on the process of balancing benefits, risks and costs.

6 HV3C-delivery by residents was guided by senior consultants' preference. In some cases, the

7 senior consultant extensively 'walked residents through' the process of balancing all relevant

8 stakes that led to their proposed diagnostic or treatment plan. In other situations, the senior

9 consultant stated their opinion of what they considered to be appropriate care without further explanation. Although residents not always understood nor agreed with the senior consultant, in general they did not request insight in the senior consultant' considerations regarding what was deemed appropriate. Residents tended to execute the advice of the senior consultant with little countering of the consultants' judgment.

Variation between senior consultants was prominent and recognizable for residents and was sometimes considered confusing especially in the eyes of junior residents. Senior residents used these differences to get agreement on their own proposed plan by being deliberate in whose senior consultant's advice they sought in certain cases, as mentioned by resident R17 in an informal interview. you have to get to know the bosses, so you know how they work. At some point you know the preferences of every senior physician, and if you have a certain plan in mind, you just call the senior consultant that you think is likely to agree with your plan... Sometimes you think it is nonsense to do something and then you just need a senior consultant who agrees with you.' 
(Fieldnotes, February 22, 2018)

2

3 Three observed learning opportunities regarding the process of balancing benefits, risks and

$4 \quad$ health care costs.

5 Based on the analysis of our observations, informal and formal interviews, it became apparent

6 that there were three main areas for learning which could be improved. First, although residents

7 and staff-members raised questions regarding what constitutes high-value, cost-conscious care,

8 we observed that questions regularly remained unanswered or undeliberated. In these situations,

9 conversations were discontinued (for example by raising a different question) or paused ('we

should check that'), without revisiting raised questions or checking/changing the course of action. Our observations also demonstrated questions followed by (collective) discussions, explicating the process of balancing benefits, risks and costs of care delivery. We asked both residents and supervisors how questions related to care delivery could be enhanced to facilitate residents' learning. Residents shared that they were in need of a more structural review of patient cases, followed by an organized overview of benefits, risks and costs of the case at hand. This could be done for example during the morning handover when discussing a patient case.

17 Secondly, decision making often was based on assumptions about costs without efforts to check

18 them. This was observed for example when costs were considered 'high' yet actual amounts

19 were not known or the meaning of commonly used terminology (for example what do we mean by 'bedrest') was not understood or defined. Thirdly, face-to-face conversations about care delivery were absent in instances where the line of reasoning was not clear for either staff or residents. Although senior consultants were sometimes openly critical to residents about how colleagues balanced benefits, risks and costs of care delivery, this did not result in a face-to-face

24 conversation about the delivered care and consequently did not result in a take-home message

25 for residents. For example, critiques often ended with comments such as; "they probably had $a$ 
1 good think about it" or "let's continue with the next case". Supervisors confirmed that

2 especially formal meetings created interesting teaching opportunities but were hesitant to

3 deepen the discussion in those meetings. Supervisors motivated this by describing how they

4 aimed to maintain a safe learning environment (do not give the resident the impression their

5 decision was 'false') while also exposing residents to the uncertainty that is present in care

6 delivery (modelling that there is more than one 'correct' treatment decision).

7

8

\section{Discussion}

\section{Summarising}

Training residents to provide $\mathrm{HV} 3 \mathrm{C}$ is essential for the sustainability of healthcare systems. ${ }^{2,5,9,10}$ This study explored how the workplace setting is related to the residents' HV3Cdelivery. Our results demonstrated that costs are not structurally considered in the process of care delivery. Another finding was the strong influence of the senior consultants' opinion regarding what is considered high-value, cost-conscious care on the resident. Furthermore, learning opportunities regarding $\mathrm{HV} 3 \mathrm{C}$ were identified; elaboration on questions raised concerning HV3C, checking information about costs that are used in discussions about HV3C, and having a more open and explicit discussion about HV3C.

\section{Insight in relevant health care costs}

The importance of knowledge-transmission for the training of high-value, cost-conscious care delivery has been emphasized in previous research. ${ }^{7,9}$ We observed that physicians aim to make health care costs part of the discussion, yet lack information to do so highlighting the importance of knowledge of health care costs in particular. Besides the lack of formal 
1 education, another known hurdle for knowledge transmission is the complexity of health care

2 economics and the lack of transparency of costs in health care systems. ${ }^{33}$

3

\section{The consultant as leading role model}

5 The leading role of the senior consultant in health care delivery in general, ${ }^{9,19,20}$ and HV3C

6 specifically ${ }^{9,33}$ has been previously identified. Through observing role models' care delivery

7 residents learn professional behaviours, particularly from those senior consultants that match

8 their personal views. ${ }^{34}$ Data-analysis demonstrates that senior residents intentionally seek

9 advice from senior consultants who are likely to share their views on HV3C-delivery.

10 Training opportunities lie in pursuing a workplace setting where senior consultants

11 deliberately assist residents in explicating their reasoning regarding HV3C, with or without

sharing the same view. This can be achieved by inviting residents to discuss, assess and reflect on future and past care delivery. Practice variations between consultants and departments could function as a starting point for these discussions and reflections, ${ }^{35,36}$ especially when residents express that they doubt if care delivery meets HV3C standards.

\section{Workplace culture}

Our results point to the absence of a culture that allows to openly question the line of reasoning of colleagues. Residents' and staff's tendency to favour agreement over critical discussions could explain this finding. Research findings indeed indicate that striving for harmony may interfere with the quality of post-graduate medical education and quality of care. ${ }^{37}$ Specifically, engaging in constructive discussions with senior consultants may be challenging in a workplace setting that is considered to be hierarchical. ${ }^{38}$ It is not surprising that the current workplace setting is not familiar with discussing care delivery from a HV3C 
1 perspective since issues of accessibility and affordably of health care are recent. Nevertheless,

2 current budgetary crises in most health care systems urge for brisk culture change. To initiate

3 a culture change, we suggest focussing interventions on senior consultants and other staff

4 members. Changing the overarching culture and stimulating residents to actively engage in

$5 \mathrm{HV} 3 \mathrm{C}$ is desirable. Therefore, future research should investigate how departments can be

6 supported in developing a critical attitude towards care delivery in light of HV3C. Action

7 research ${ }^{39}$ can be a suitable strategy to challenge conventional thinking about HV3C in the

8 clinical setting. In such design, integrating an independent external expert to regularly

9 question care delivery, and guide group discussions in an open and tolerant manner, may

10 speed up consciousness of value for patients, costs and the urge for bottom up system change.

11 This 'devils' advocate' could help to fill in the opportunities detected in this study;

12 elaboration on questions raised concerning HV3C, checking information about costs that is

13 used in discussions about HV3C, and having a more open and explicit discussion about

14 HV3C. The ultimate achievement would be that staff members and residents would take over this role and challenge each other to underpin their decision-making process in $\mathrm{HV} 3 \mathrm{C}$ or structurally reflect on HV3C-delivery via group-discussions.

The main strength of this study is the use of ethnography to gain insight in how the workplace setting is related to residents' HV3C-delivery. A major strength of ethnography is the ability to observe things that those who are routinely involved may not see as well as collecting data that participant might not be willing to share with researchers. ${ }^{26}$ Another strength is the rigorous performance of our data collection and analysis, in compliance with quality criteria of

24 qualitative research. Our study has several limitations. Participating residents might have been 25 more favourable towards HV3C-delivery, as they were aware of the researchers' presence and 
1 the research goal, and observations might be an overestimation of the role of HV3C in residency

2 training. A second limitation is the restricted scope of our ethnographic research, since the

3 observations solely took place within one single specialty in one single hospital. We aimed to

4 mitigate this limitation by providing a description of the setting in which the research was

5 performed. Additionally, our findings were assessed by a member of our research team who is

6 familiar with the context but not a member of it. Nevertheless, extrapolation to other residency

7 programs or departments must be done prudently.

\section{Conclusions}

10 Our study emphasizes that the opportunities and potential to train residents to deliver high-

11 value, cost-conscious care in the workplace are present. The challenge resides in capitalizing on

12 these opportunities. We suggest departments to consult external experts to facilitate discussions regarding high-value, cost-conscious care to contribute to informal learning and to create a workplace setting in which high-value, cost-conscious care-delivery is prioritized.

Acknowledgements: The research team would like to thank the participating department for

17 their cooperation.

Disclosure of interest: nothing to declare.

Contribution to Authorship: All assigned co-authors fulfilled their duties as described in the

Details of Ethics Approval: The Ethical Review Board of the Netherlands Association for

21 Medical Education (NVMO) approved this study on August 24, 2017, under file number 881.

\section{Funding: None}

\section{References:}

24 1. Jeurissen P, Maarse H, Tanke M. Betaalbare zorg. Vol 1. Den Haag: SDU; 2018. 
1 2. Berwick DM, Hackbarth AD. Eliminating waste in US health care. JAMA.

2 2012;307(14):1513-1516.

3 3. Holmboe E. ACGME milestones framework. https://www.acgme.org. Published 2015.

$4 \quad$ Accessed2019.

5 4. Blumenthal D. Controlling health care expenditures. N Engl J Med. 2001;344(10):766-

$6 \quad 769$.

7 5. Cooke M. Cost consciousness in patient care--what is medical education's responsibility? N Engl J Med. 2010;362(14):1253-1255.

9 6. McDaniel CE, White AA, Bradford MC, et al. The High-Value Care Rounding Tool: Development and Validity Evidence. Acad Med. 2018;93(2):199-206.

11 7. Stammen LA, Stalmeijer RE, Paternotte E, et al. Training Physicians to Provide HighValue, Cost-Conscious Care: A Systematic Review. JAMA. 2015;314(22):2384-2400.

13 8. Weinberger SE. Educating trainees about appropriate and cost-conscious diagnostic testing. Acad Med. 2011;86(11):1352.

9. Stammen LA, Slootweg I, Stalmeijer R, et al. The Struggle Is Real: How Residents Learn to Provide High-Value, Cost-Conscious Care. Teach Learn Med. 2019:1-10.

10. Owens DK, Qaseem A, Chou R, Shekelle P, Clinical Guidelines Committee of the American College of P. High-value, cost-conscious health care: concepts for clinicians to evaluate the benefits, harms, and costs of medical interventions. Ann Intern Med.

11. Horwitz LI, Masica AL, Auerbach AD. Introducing Choosing Wisely(R): Next steps in improving healthcare value. J Hosp Med. 2015;10(3):187-189. to foster high-value, cost-conscious care. Ann Intern Med. 2012;156(2):147-149. 
1 13. Levinson W, Born K, Wolfson D. Choosing Wisely Campaigns: A Work in Progress.

2 JAMA. 2018;319(19):1975-1976.

14. Otte J. Less is More Medicine. ww.lessismoremedicine.com/. Published 2012. Accessed 11/07/2019.

15. Council GM. Outcomes for graduates. General Medical Counsil. Published 2018. Accessed 11/07/2019, 2019.

16. Frank JR SL, Sherbino J,. CanMEDS-framework. Royal college of physicians and surgeons of Canada;2015.

17. Caitlin Clancy M, C. Jessica Dine, Donna Williams, Cynthia D. Smith. High value care curriculum 4.0. https://www.acponline.org/clinical-information/high-valuecare/medical-educators-resources/newly-revised-curriculum-for-educators-andresidents-version-40. Published 2019. Accessed 11/07/2019, 2019.

18. Ryskina KL, Dine CJ, Kim EJ, Bishop TF, Epstein AJ. Effect of Attending Practice Style on Generic Medication Prescribing by Residents in the Clinic Setting: An Observational Study. J Gen Intern Med. 2015;30(9):1286-1293.

19. Morris CB. Understanding medical education: evidence, theory and practice: the association for the study of medical education. 2010 .

20. Stammen L. How do attending physicians prepare residents to deliver high-value, costconscious care? Acad Med. 2019.

21. Dornan T, Mann KV, Scherpbier AJ, Spencer JA. Medical Education: Theory and Practice E-Book. Elsevier Health Sciences; 2011.

22. Asch DA, Nicholson S, Srinivas S, Herrin J, Epstein AJ. Evaluating obstetrical residency programs using patient outcomes. JAMA. 2009;302(12):1277-1283. 
1 23. Chen C, Petterson S, Phillips R, Bazemore A, Mullan F. Spending patterns in region of residency training and subsequent expenditures for care provided by practicing physicians for Medicare beneficiaries. JAMA. 2014;312(22):2385-2393.

24. Wong BM, Holmboe ES. Transforming the Academic Faculty Perspective in Graduate Medical Education to Better Align Educational and Clinical Outcomes. Acad Med. 2016;91(4):473-479.

25. Reeves S, Kuper A, Hodges BD. Qualitative research methodologies: ethnography. BMJ. 2008;337:a1020.

26. Savin-Baden M, Major C-H. Qualititaive Research: The Essential Guide to Theory and Practice. Qualitative Research: The Essential Guide to Theory and Practice Routledge. 2013.

27. Atkinson P, Pugsley L. Making sense of ethnography and medical education. Med Educ. $2005 ; 39(2): 228-234$

28. Bewustzijnsproject. Bewustzijnsproject. https://www.bewustzijnsproject.nl. Published 2015. Accessed 11/07/2019, 2019.

29. Reulink N, Lindeman L. Kwalitatief onderzoek. Participerende observatie, interviewen. 2005 .

30. Whitehead TL. Basic classical ethnographic research methods. Cultural ecology of health and change. 2005;1:1-29.

31. Geertz C. Thick description: Toward an interpretive theory of culture. In: The cultural geography reader. Routledge; 2008:41-51.

32. Varpio L, Ajjawi R, Monrouxe LV, O'Brien BC, Rees CE. Shedding the cobra effect: problematising thematic emergence, triangulation, saturation and member checking. Med Educ. 2017;51(1):40-50. 
1 33. Stammen LA, Driessen EW, Notermans CC, Scheele F, Stassen LP, Stalmeijer RE. How Care? Academic Medicine. 2019.

4 34. Jochemsen-van der Leeuw HR, van Dijk N, van Etten-Jamaludin FS, Wieringa-de Waard M. The attributes of the clinical trainer as a role model: a systematic review. Academic Medicine. 2013;88(1):26-34.

7 35. Holmboe E, Ginsburg S, Bernabeo E. The rotational approach to medical education: time to confront our assumptions? Med Educ. 2011;45(1):69-80.

9 36. Djulbegovic B, Hamm RM, Mayrhofer T, Hozo I, Van den Ende J. Rationality, practice variation and person-centred health policy: a threshold hypothesis. J Eval Clin Pract. 2015;21(6):1121-1124.

12 37. Janss R, Rispens S, Segers M, Jehn KA. What is happening under the surface? Power, conflict and the performance of medical teams. Med Educ. 2012;46(9):838-849.

38. Janss R, Rispens S, Segers M, Jehn KA. What is happening under the surface? Power, conflict and the performance of medical teams. Medical education. 2012;46(9):838-849. research. Bmj. 2008;337:a567. 